\title{
Peer Education Group Intervention to Reduce Psychological Insulin Resistance: A Pilot Mixed- Method Study in a Chinese Population
}

\author{
Ka Yan Or • Benjamin Hoi-Kei Yip • Chi Hang Lau • Hing Han Chen • \\ Yuk Wah Chan $\cdot$ Kam Pui Lee $\mathbb{D}$
}

Received: October 18, 2017 / Published online: December 7, 2017

(c) The Author(s) 2017. This article is an open access publication

\begin{abstract}
Introduction: Psychological insulin resistance (PIR) is common among type II diabetes (DM) patients. Although interventions to reduce PIR have been suggested, there is no standardized intervention to reduce PIR. This trial aimed to assess the preliminary effectiveness of a wellstructured interventional patient group (for sample size calculation for larger trials), as well as the acceptability and feasibility of this intervention group.
\end{abstract}

Methods: This study used a quasi-experimental, mixed-method approach. Fifty-three patients

Enhanced content To view enhanced content for this article go to http://www.medengine.com/Redeem/ C9FCF060726E14C9.

Electronic supplementary material The online version of this article (https://doi.org/10.1007/s13300017-0347-3) contains supplementary material, which is available to authorized users.

K. Y. Or · C. H. Lau · H. H. Chen · Y. W. Chan Department of Family Medicine, Kowloon Central Cluster, Hospital Authority, East Kowloon General Outpatient Clinic, Hong Kong, China

B. H.-K. Yip · K. P. Lee $(\bowtie)$

Jockey Club School of Public Health and Primary

Care, The Chinese University of Hong Kong, Hong

Kong, China

e-mail: 1kp032@cuhk.edu.hk with DM were recruited to an interventional group that included a general education of DM and insulin, an insulin pen demonstration, and an insulin-using peer sharing session. Each group consisted of around 15 participants and lasted for $2 \mathrm{~h}$ each. The validated Chinese version of the insulin treatment appraisal scale (C-ITAS) was administered before, immediately after, and 1 month after the intervention to measure any changes in the participants' PIR. Patients were interviewed to assess the acceptability of the intervention until data saturation. Results: Repeated measures ANOVA showed that the post-intervention C-ITAS scores (immediately post group and at 1 month) were lower than the pre-intervention C-ITAS scores $(p<0.001)$. Changes in multiple attitudes toward insulin were detected before and after the group intervention. Ten patient interviews were conducted and found that the intervention was welcomed by all interviewees; no discomfort or adverse reactions were reported.

Conclusion: Preliminary results showed that patient intervention groups with general education, insulin pen demonstration, and peer sharing appeared to be safe, acceptable, and effective in reducing PIR. Larger multicenter trials are needed to generalize these findings.

Keywords: Insulin; Insulin treatment appraisal scale; Peer education group intervention; 
Psychological insulin resistance; Type 2 diabetes mellitus

\section{INTRODUCTION}

Type II diabetes mellitus (DM) is a common condition that can lead to disabling complications [1]. These complications may be prevented by effective and early DM control [2], as measured by the glycosylated hemoglobin level (HbA1c). Due to the progressive nature of DM, most patients eventually require insulin treatment [3]. Besides oral hypoglycemic agents (OHA) failure, the National Institute for Health and Care Excellence (NICE) also recommended that insulin treatment should be initiated early in patients with DM and very high HbA1c [4].

However, many patients refused insulin as a result of psychological factors. This phenomenon is called psychological insulin resistance (PIR) [5]. The underlying reasons for PIR are widely described [5]. Prevalence of PIR in Hong Kong primary care is higher than that of in Western countries and PIR is shown to be associated with many psychosocial factors [6-8]. PIR can be measured by validated instruments such as the insulin treatment appraisal scale (ITAS) [9]. The ITAS was translated and validated in Hong Kong (C-ITAS) [7].

Despite studies being available on ways to tackle PIR—such as identifying obstacles via administration of PIR questionnaires (e.g., ITAS) [10], counselling strategies according to patients' attitude [11], switching insulin vials to insulin pen and starting at a lower dose of insulin [10]_PIR remains difficult to tackle and no widely used, recommended, or structured program to tackle it is available. As the Hong Kong Government funded general outpatient clinics (GOPC) have one of the shortest consultation times in the world, which is around 7 min per consultation (and often as short as 2-3 min) [12], an individual counselling approach may not be feasible.

DM group education $[13,14]$ and peer education $[15,16]$ were shown to improve DM outcomes (e.g., HbA1c) and were cost-effective when compared to individual counselling and to standard care, respectively. The involvement of peers in education is theoretically sound because healthcare professionals often have wrong perceptions of patients' reasons which underlie PIR [17]; and patients may feel more empathized with when counselled by their peers [18]. According to social cognitive theory, learning occurs not by simply trying different behaviors, but by replicating actions from a role model (an insulin user in the context of the current study) [19].

As there is no well-recognized standardized intervention to ameliorate PIR, this pilot study examined the preliminary effectiveness of a standardized group intervention involving peer education and insulin pen demonstration in DM patients to reduce PIR. As a pilot study, the feasibility and acceptability of this group intervention were also assessed. We hypothesized that this standardized group intervention is acceptable to patients and is effective. This trial therefore provides essential information for undertaking larger trials.

\section{METHODS}

This study used a quasi-experimental approach, employing mix-method analysis (collection and analysis of both qualitative and quantitative data). Patients were recruited consecutively in a GOPC in Kowloon, Hong Kong when they came to the clinic for doctors' consultations. Patients who (1) were older than 18 years of age, (2) were diagnosed with type II DM, as defined by the American Diabetes Association [20], (3) were not currently using insulin, (4) either had refused insulin despite the fact that insulin had been recommended by the case doctor [4], or on high dose of oral hypoglycemic agents, as defined by either on maximum dose of metformin or more than half of maximum recommended dose of metformin and sulfonylurea, and (5) could communicate in fluent Cantonese, were included. Patients who had physi$\mathrm{cal} / \mathrm{mental}$ illnesses that hindered them from completing the questionnaire or communicate in the group were excluded, e.g., dementia, deafness, and severe visual problems. The recruitment process was stopped after an adequate sample size was obtained. Reasons for 
refusal were recorded by the recruiting doctors and nurses. DM complication screening (DMCS) or individual counselling (DMIC) was arranged for all participants as dictated by the department of family medicine (Hong Kong Hospital Authority) protocol in order to standardize their multidisciplinary intervention by the DM nurse.

The research was approved by Kowloon West Cluster Research Ethics Committee, Hospital Authority, Hong Kong. All procedures followed were in accordance with the ethical standards of the responsible committee on human experimentation (institutional and national) and with the Helsinki Declaration of 1964, as revised in 2013. Written informed consent was obtained at the time of recruitment from all patients for being included in the study. Demographic data collected on recruitment included marital status, educational level, occupation, whether or not they lived with family, if they had friends/family using insulin, and if they had any side effects when using insulin. Clinical data, such as sex, age, baseline DM control (HbA1c), lipid level including low-density lipoprotein level(LDL), hypertension, presence of DM complications, and years of DM diagnosed (according to last visit before recruitment), were traced using the computerized medical record system (CMS). Participants completed the C-ITAS questionnaire once they were recruited.

\section{Intervention}

As discussed above, we hypothesized that a group intervention with peer education constitutes an effective intervention. According to social cognitive theory, behavioral changes occur when people observe and learn from the actions of others, following individual cognitive processes [19]. This process is facilitated by adequate knowledge and self-efficacy so "that one can exercise control over a health habit" [19]. Therefore, each session followed a protocol which included (1) general introduction to DM and insulin using a standardized PowerPoint (providing knowledge and enhance self-efficacy) (see Appendix II); (2) sharing by an insulin user (providing learning from a role model); and
(3) demonstration of use of insulin pens by the DM nurse (providing knowledge and enhance self-efficacy). The participants could practice the use of the insulin pen if they wished. As previously mentioned, group and peer education appear to be effective for educating patients with DM. This structured program would not only convey knowledge but also address their fear of insulin through peer sharing and directly experiencing the insulin pen.

The insulin motivational groups were held on Saturday mornings in the GOPC. In total, six groups were held. Each group aimed to consist of about 15 patients and lasted for approximately $2 \mathrm{~h}$, and each was led by the doctor and an experienced advanced practice nurse, who has experience in conducting insulin counselling. Fidelity checks for all the groups were conducted by the principal investigator to ensure that the material presented was consistent.

The participants were asked to complete the C-ITAS questionnaire at the end of group session. They were interviewed by phone by another independent doctor in the clinic to fill in the C-ITAS, around 1 month after the group meeting. The number of patients who started to use insulin in the study group was collected about 2-3 months after the group intervention using the CMS.

\section{Instrument: Insulin Treatment Appraisal Scale (C-ITAS [7])}

The ITAS is a 20-item instrument that contains 16 negative and 4 positive statements that appraise insulin treatment. Each statement is ranked using a five-point Likert-type scale from 1 to 5. Positive scores are reversed to allow for summation. The total possible score ranges from 0 to 80 [9]. A higher score signifies a more negative appraisal of insulin. The ITAS was developed for clinical use to measure PIR. No cutoff score was used to diagnose PIR.

\section{To Assess Acceptability and Feasibility of the Intervention}

To assess acceptability by participants, attendance and qualitative information on the 
experience of being in the group were collected. Participants were interviewed in person until data saturation, following preliminary analysis of quantitative data. In this study, a small number of patients started insulin after the group. To include these experiences, they were all invited for interview. Otherwise, patients who had attended the group near the end of the trial were preferred because they were more likely to remember the intervention. This semistructured interview allowed us (1) to understand the experience of the patients attending the group and (2) to explain the results of the quantitative data. The interview was conducted by a research assistant trained by the principal investigator. Semi-structured interviews were conducted in accordance with the interview guide (Table 1).

\section{Sample Size}

A pilot study involving one patient group was conducted. At a power of $85 \%$ and type I error at $5 \%, 50$ participants were needed for total C-ITAS score to drop by more than 6 points. Previous studies showed that a drop of 3-8 points of the ITAS score among DM patients was associated with subsequent willingness to start on insulin [21-23].

\section{Statistical Analysis}

SPSS 21.0 was used for statistical analysis. Demographic data was presented with the mean and standard deviation for continuous data and proportion for categorical data. Repeated measures ANOVA was utilized to determine if there was a significant change in C-ITAS total scale or subscale scores throughout the three time points (on recruitment, immediate post-group, and 1 month after the group session). Previous studies $[7,24]$ suggested that analyzing the data using the positive and negative scale of C-ITAS may be more informative. Demographic data was entered into the ANOVA model in order to determine the relationship between different demographic data and the change in C-ITAS scores.

McNemar's test was used to detect attitude change in each C-ITAS statement before and after the intervention group. Each C-ITAS item was dichotomized as "disagree" and "neutral" (scores of 1-3) or "agree" (scores of 4-5); this dichotomy was created to identify participants who agree with each statement. McNemar's test was considered the most suitable test for comparison of the dichotomous variable of a related pair.

Table 1 Semi-structured interview for participants

\begin{tabular}{l}
\hline Qheme \\
$\begin{array}{l}\text { Acceptability of the } \\
\text { group }\end{array}$ \\
How did you feel when you were invited to attend the group? \\
Why did you come to the group? \\
Was there anything in the group that made you uncomfortable/or you found that was not as well \\
done? Any complaints? \\
What was the most useful/best part of the group? Any suggestions for improvement? \\
If you found the group useful, how did it decrease your fear about insulin? Or how did you know \\
more about the positive aspects/benefits about insulin? \\
What were your major fears about insulin? Did the group address that? How? \\
Did your perception of insulin change after the group up until now? What's your perception of \\
insulin now? How was this perception affected/not affected by the group? \\
Can you still remember what was presented in the group?
\end{tabular}


Data from the interviews was analyzed using thematic analysis, and interviews were audiorecorded, transcribed, and coded thematically. Two researchers then independently crosschecked the coding for reliability. If there was any theme that could not be settled by the two investigators $(\mathrm{KYO} / \mathrm{KPL})$, it was settled by the third investigator (BHKY).

\section{RESULTS}

Out of 91 patients who agreed to participate in the study, 27 did not show up for the intervention and were lost to the follow-up (Fig. 1). Nine patients left before the completion of intervention (end of the group) because of personal issues (e.g., caring of family members). Two participants were unable to be interviewed by phone (i.e., defaulted phone interview) at 1 month because the participant refused to talk about insulin $(n=1)$ and was unable to be reached $(n=1)$.

The reasons for participants being unwilling to join the study during recruitment included (1) no time to attend; (2) no interest to attend any education group; (3) adamant that they would not change their mind to accept insulin after the DM group; (4) strongly believe to have known all the principles about insulin already; and (5) fear of being persuaded to start insulin after the group.

\section{Demographics of Participants}

Fifty-three percent (53\%) of participants were female and $89 \%$ had at least a primary education or above. Most of them had at least one complication of DM or macrovascular/microvascular cardiovascular complication (62\%) (Table 2).

\section{Effectiveness of the Motivational Group}

Repeated measures ANOVA found that the pregroup means of C-ITAS (score 37) were significantly higher than that of the post-group (score 26) and 1 month after post-group (score 30) $(p<0.001)$. Analysis by repeated measures ANOVA found that the trends of change in both positive appraisal subscale $(p=0.039)$ and negative subscale $(p<0.001)$ were statistically significant (Fig. 2).

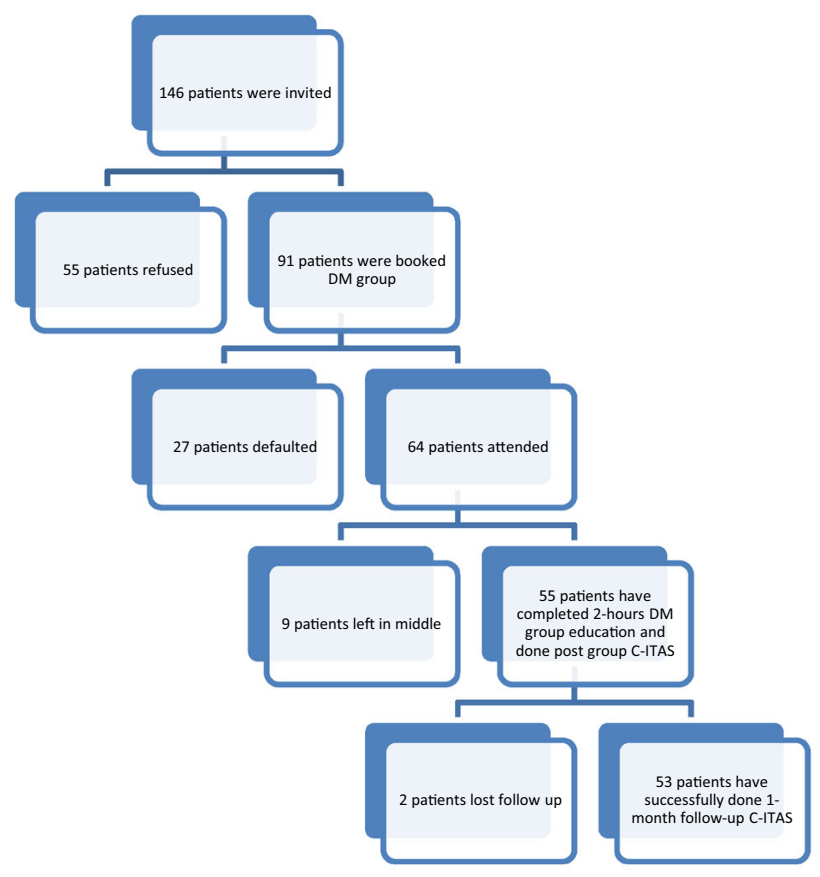

Fig. 1 Recruitment flowchart 
Table 2 Demographics of participants

\begin{tabular}{|c|c|c|c|c|c|}
\hline & \multicolumn{2}{|l|}{ Range } & \multicolumn{2}{|c|}{ Mean } & SD \\
\hline Age (years) & \multicolumn{2}{|l|}{$32-87$} & \multicolumn{2}{|l|}{65.6} & 10.2 \\
\hline Years since DM diagnosis (year) & \multicolumn{2}{|l|}{$1-33$} & \multicolumn{2}{|l|}{11.4} & 6.9 \\
\hline \multirow[t]{2}{*}{ Last HbAlc level } & \multicolumn{2}{|c|}{$6.1 \%(43 \mathrm{mmol} / \mathrm{mol})$ to $10.6 \%(92 \mathrm{mmol} / \mathrm{mol})$} & \multicolumn{2}{|c|}{$7.4 \%(57 \mathrm{mmol} / \mathrm{mol})$} & $0.8 \%$ \\
\hline & & \multicolumn{2}{|l|}{ Data } & \multicolumn{2}{|c|}{ Proportion (\%) } \\
\hline \multicolumn{2}{|l|}{ Age } & \multicolumn{2}{|l|}{ Age $\geq 65$} & \multicolumn{2}{|l|}{60.0} \\
\hline \multicolumn{2}{|l|}{ HbAlc } & \multicolumn{2}{|c|}{$\mathrm{HbAlc}>7 \%(53 \mathrm{mmol} / \mathrm{mol})$} & \multicolumn{2}{|l|}{61.8} \\
\hline \multicolumn{2}{|l|}{ Sex } & \multicolumn{2}{|l|}{ Female } & \multicolumn{2}{|l|}{52.7} \\
\hline \multirow{4}{*}{\multicolumn{2}{|c|}{ Education level }} & \multicolumn{2}{|l|}{$<$ Primary } & \multicolumn{2}{|l|}{10.9} \\
\hline & & \multicolumn{2}{|l|}{ Primary } & \multicolumn{2}{|l|}{45.5} \\
\hline & & \multicolumn{2}{|l|}{ Secondary } & \multicolumn{2}{|l|}{40.0} \\
\hline & & \multicolumn{2}{|l|}{ University or above } & \multicolumn{2}{|l|}{3.6} \\
\hline \multirow[t]{4}{*}{ Marital status } & & Single & & 16.4 & \\
\hline & & Married & & 60.0 & \\
\hline & & Divorced & & 3.6 & \\
\hline & & Widowed & & 20.0 & \\
\hline Working status & & Working & & 32.7 & \\
\hline Family status & & Lives alone & & 59.1 & \\
\hline Used insulin before? & & No & & 100.0 & \\
\hline Family/friends using insulin? & & No & & 83.6 & \\
\hline Heard of side effects of insulin fr & m family/friends & Yes & & 3.6 & \\
\hline History of hypertension & & Yes & & 72.7 & \\
\hline History of hyperlipidemia & & Yes & & 89.1 & \\
\hline Use of metformin & & Yes & & 100.0 & \\
\hline Use of SU & & Yes & & 94.5 & \\
\hline Use of DPP-4 & & Yes & & 27.3 & \\
\hline Smoking & & Non-smoker & & 74.5 & \\
\hline & & Smoker & & 12.7 & \\
\hline & & Ex-smoker & & 12.7 & \\
\hline $\begin{array}{l}\text { History of cardiovascular disease } \\
\text { coronary artery, cerebrovascular } \\
\text { vascular diseases }\end{array}$ & $\begin{array}{l}\text { (VD) including } \\
\text { r peripheral }\end{array}$ & Yes & & 7.3 & \\
\hline History of DM retinopathy (DM & & Yes & & 40.0 & \\
\hline History of microalbuminuria ( $\mathrm{M}$ & & Yes & & 32.7 & \\
\hline
\end{tabular}


Table 2 continued

\begin{tabular}{lcc}
\hline & Data & Proportion (\%) \\
\hline History of impaired foot sensation (FS) & Yes & 5.5 \\
Any complications (CVD/DMR/MA/FS) & Yes & 61.8 \\
The three most common negative appraisals of insulin in C-ITAS & \\
Q6. Fear of injecting with needle & Agree & 76.4 \\
Q14. Injection is painful & Agree & 52.7 \\
Q18. Family/friends more concerned & Agree & 52.7 \\
\hline
\end{tabular}

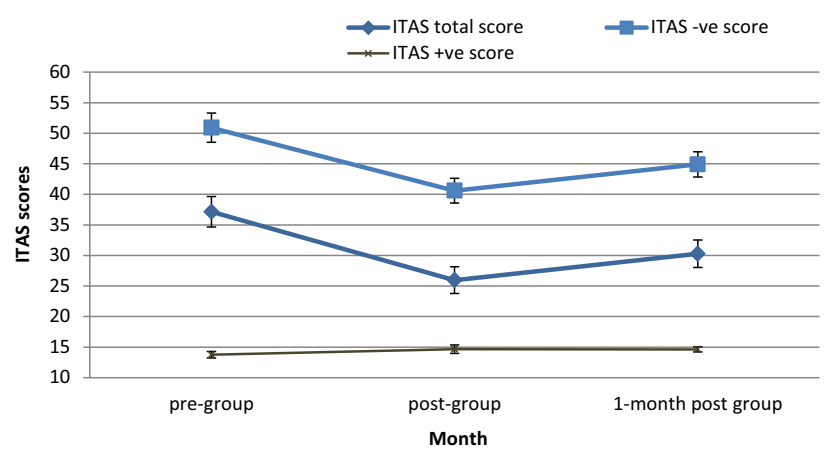

Fig. 2 ITAS score changes. Data was presented with mean (the dot) at each time point with $95 \%$ confidence interval (vertical line). Four participants were excluded in analysis

The changes of the C-ITAS total score or positive/negative scores over time were not significantly different between different groups, age, sex, marital status, education level, working status, smoking status, if family or friends had history of use of insulin, years of DM diagnosis, latest HbA1c level, or co-morbidities/complications (data not shown).

In total, five participants agreed to or had started insulin therapy after attending the motivation group. Their change in total C-ITAS score $(p=0.48)$ over time was not significantly different from those of other participants.

\section{Change of C-ITAS Attitudes}

As defined by the C-ITAS statements, there were changes in multiple attitudes before and after the group intervention. Some of the effects because of absence of data at 1 month post group. Repeated measures ANOVA requires complete data in all three time points

persisted at 1 month after the motivational group (Table 3 ).

\section{Acceptability of the Intervention}

Ten patients were interviewed and data saturation was achieved. There was high acceptability and the intervention was welcomed by interviewees; no discomfort or adverse reactions were detected. Some of them experienced changes in their perception of insulin after the group, but others admitted that they could not remember the information presented in the group. Some commented that fears specific to individuals about insulin were not addressed in the group. Various suggestions to further improve the group, mostly focused on ways to enhance memory about information presented, were made by a few participants (see 
Table 3 Changes of attitude before and after the group

\begin{tabular}{|c|c|c|c|c|c|c|}
\hline ITAS statements & $\begin{array}{l}\text { Pre-group } \\
\text { Agree (\%) }\end{array}$ & $\begin{array}{l}\text { Post-group } \\
\text { Agree (\%) }\end{array}$ & $p$ value & $\begin{array}{l}\text { Pre-group } \\
\text { Agree (\%) }\end{array}$ & $\begin{array}{l}1 \text { month after } \\
\text { group } \\
\text { Agree (\%) }\end{array}$ & $p$ value \\
\hline \multicolumn{7}{|l|}{ Negative statements } \\
\hline Q1. Failed on pre-insulin therapy & 38.2 & 18.2 & $0.035^{*}$ & 39.7 & 26.4 & 0.21 \\
\hline Q2. Diabetes has gotten worse & 45.5 & 16.4 & $0.001^{*}$ & 47.2 & 24.5 & $0.023^{*}$ \\
\hline Q4. Perceived by others as more sick & 50.9 & 20.0 & $<0.001^{*}$ & 52.8 & 54.7 & 1.000 \\
\hline Q5. Life less flexible & 45.5 & 12.7 & $<0.001^{*}$ & 47.2 & 41.5 & 0.648 \\
\hline Q6. Fear of injecting with needle & 76.4 & 38.2 & $<0.001^{*}$ & 77.4 & 64.2 & 0.118 \\
\hline Q7. Risk of hypoglycemia & 27.3 & 18.2 & 0.383 & 28.3 & 24.5 & 0.815 \\
\hline Q9. Cause weight gain & 12.7 & 18.2 & 0.607 & 13.2 & 17.0 & 0.774 \\
\hline Q10. Takes time and energy & 38.2 & 10.9 & $0.001^{*}$ & 39.6 & 24.5 & 0.134 \\
\hline Q11. Give up activities I enjoy & 27.3 & 5.5 & $0.008^{*}$ & 27.3 & 15.1 & 0.118 \\
\hline Q12. My health deteriorates & 38.2 & 12.7 & $0.004^{*}$ & 39.6 & 17.0 & $0.012^{*}$ \\
\hline Q13. Injecting is embarrassing & 38.2 & 18.2 & $0.035^{*}$ & 39.6 & 38.5 & 1.000 \\
\hline Q14. Injecting is painful & 52.7 & 14.5 & $<0.001^{*}$ & 52.8 & 41.5 & 0.238 \\
\hline Q15. Difficult to always inject correctly & 50.9 & 16.4 & $<0.001^{*}$ & 52.8 & 34.0 & 0.052 \\
\hline Q16. Difficult to fulfill responsibilities & 29.1 & 7.3 & $0.008^{*}$ & 30.2 & 28.3 & 0.549 \\
\hline Q18. Family/friends more concerned & 52.7 & 27.3 & $0.004^{*}$ & 54.7 & 45.3 & 0.332 \\
\hline Q20. More dependent on doctor & 49.1 & 16.4 & $<0.001^{*}$ & 50.9 & 48.1 & 0.774 \\
\hline \multicolumn{7}{|l|}{ Positive statements } \\
\hline Q3. Prevent complications & 58.2 & 81.8 & $0.004^{*}$ & 58.5 & 75.5 & $0.049^{*}$ \\
\hline Q8. Improves health & 56.4 & 76.4 & 0.054 & 56.6 & 79.2 & $0.004^{*}$ \\
\hline Q17. Helps to control blood glucose & 65.5 & 78.2 & 0.248 & 64.2 & 84.9 & $0.013^{*}$ \\
\hline Q19. Helps to improve energy levels & 20.0 & 47.3 & $0.001^{*}$ & 18.9 & 39.6 & $0.013^{*}$ \\
\hline
\end{tabular}

${ }^{*}$ Represent significant $p$ value at $<0.05$

Appendix 1). The qualitative and quantitative findings complement each other (Table 4).

\section{DISCUSSION}

This trial provided evidence of the preliminary effectiveness of a well-structured programme to decrease PIR as shown by an international validated instrument, and the intervention was welcomed by patients. As previously stated, there was previously no standardized intervention for PIR. Most previous research suggested individual counselling to target the underlying reasons behind PIR [11], but this is often not possible because our consultation time is very short. We developed a new group intervention to fit into primary care because previously suggested interventions, although effective, were not suitable for primary care: for example, cognitive restructuring psychotherapy [25] would require special training and is not pragmatic in 
Table 4 A comparison of the qualitative and quantitative results

\begin{tabular}{lc}
\hline Quantitative data & Qualitative data (interview) \\
$\begin{array}{l}\text { A significant decrease in psychological insulin resistance that } \\
\text { persisted at 1 month after the group was held }\end{array}$ & $\begin{array}{c}\text { For those participants who could retain information until } \\
\text { the interview, a few perceptional changes about insulin } \\
\text { were detected }\end{array}$ \\
$\begin{array}{l}\text { Multiple attitude changes were detected in the ITAS } \\
\begin{array}{l}\text { A bounce back in the ITAS score was seen when comparing } \\
\text { pre-group, post-group, and 1 month after group ITAS } \\
\text { scores }\end{array}\end{array}$ & $\begin{array}{c}\text { A few patients admitted that they could not remember what } \\
\text { in the group did not have perceptional changes }\end{array}$ \\
& $\begin{array}{c}\text { A variety of suggestions were raised by patients to help recall } \\
\text { or deepen their understanding about insulin }\end{array}$
\end{tabular}

our primary care setting; other studies using experimental learning theory (with patients learning about insulin during hospitalization and with close supervision) are not applicable to our primary care practice [26]. Our intervention is similar to a recently published nurse-led group intervention with mock insulin injections in the USA, yet our trial was the first to describe an intervention involving peer education [27]. Peer education was treasured by many participants in our trial (see Appendix 1). Our study also only involved a one-off group intervention which can be more cost-effective.

The drop in the ITAS score after intervention was shown to predict insulin initiation [21, 28]. The drop in ITAS in the current study was larger or comparable to other studies. ITAS is known to be sensitive to change after the initiation of insulin. In various studies, the negative subscale of ITAS dropped by 3.1-8.3 points after starting insulin while the positive score was not significantly different [21-23]. Another study using experimental learning theory in a Chinese hospital found that ITAS dropped in the interventional group around three points more than in the control group [26]. Depending on different time points, our current study showed that the negative/total score decreased by around 5-10 points and the positive score increased by around 1 point. Scores of individual statements (both positive and negative) in C-ITAS improved, signifying a more positive appraisal of insulin and some of the attitude changes persisted for 1 month after the group.
The change of C-ITAS score over time is worth further exploration. The C-ITAS scores improved immediately after the group intervention but the effect was not sustained after 1 month. We speculated that patients might have forgotten information provided during the DM group, which is supported by our interview data. Another possible explanation is that the patients wanted to please the nurse or the instructor of the intervention group and therefore exaggerated their response. The C-ITAS was self-administrated at post-intervention but was administrated over the phone at 1 month following the event. Therefore, how this may have affected the C-ITAS scoring is not known. Although some patients were not able to retain knowledge from the group, no definite recommendations from the patients could be concluded from the patients' interviews. In future groups, actions to enhance learning could include (1) giving out leaflets summarizing information from the PowerPoint; (2) checking understanding (e.g., a short quiz) after the PowerPoint presentation; and (3) arranging one follow-up session with the advance practice nurse (if patient agrees) at around 1 month after the intervention to answer questions and check understanding.

Although only five out of 55 patients agreed or started to use insulin at 1 month after the intervention, these results were not discouraging. It was because many patients included in the intervention had not yet received maximal dose of combined DM medications-i.e., they 
may still have time to consider use of insulin. They may change their decision when their DM control worsens or when they are strongly advised by their case doctors to start taking insulin. Acceptance is also a process which takes time and the initiation rate may increase over time. Previous trials usually assess initiation rate at 1 year [21].

The group intervention was well accepted by patients. However, it was clear from the interview that ways to help patient to recall information learned in the group are needed, because many patients could not retain the information that they learned for more than a few months. An individualized approach may be needed because different patients suggested different solutions (see Appendix 1). It might be advisable for healthcare professionals to arrange follow-ups shortly after the group events to identify patient needs, so that the patient can learn and remember more about insulin. An individualized approach on follow-up may also be more effective because some of the reasons behind patients' PIR may be too specific to be included and discussed in the group (e.g., Patient 2: "can insulin be used in patients with skin allergy?"). The dropout rate of 30\% was comparable to other educational groups in GOPCs, contributed to by the absence of a reminder system and the 2 months waiting time between recruitment and the intervention. Because all groups were held on Saturday mornings (because of limited manpower during weekdays), many participants expressed difficulties in applying for leave. The intervention is considered feasible because dropout rates were similar to other interventions in primary care and this may improve if the intervention can be held on other days of the week.

The major weakness of this study was that it involved only one center, had a small sample size, and there was no control group, which may limit the generalizability of the results. Indeed, the small sample size hinders us from drawing definite conclusions. However, as a pilot study, our aim was to assess the preliminary effectiveness of an intervention and to assess its feasibility and acceptability. The sample size was also already calculated from data of one pilot group and using power of 0.85 . This aim was achieved and a larger, multicenter study will be needed. The lack of control group limited our interpretation to account for various potential bias and effects (e.g., natural acceptance of insulin by the time instead of the group effect). Yet, these patients followed up for their DM for years at the same clinic. It was unlikely that there were other external factors that decreased their PIR besides the group intervention.

Another limitation of this study was that a significant proportion of patients refused to participant in group education at all. This may limit the generalizability of our study results to patients with very high PIR and/or poor insight into their illnesses. This could be due to our recruitment method: as a self-funded study, the recruiting doctors in GOPC only asked very briefly if their patients were interested in joining this group intervention during the 5-min medical consultation. The response rate would improve if participants are recruited in a family medicine specialist DM clinic where the consultation time for each patient can be up to 20 min, or if recruitment is conducted by a research assistant when funding is available.

As for the strength of this study, it was the first structured program that involved peer education to improve PIR. ITAS, which had a strong validation history, is the recommended measure for PIR for clinical use or research in a recent review [29] and predicts insulin initiation [21]. The current study also employed a mix-method research strategy to help explain data and assess acceptability.

\section{CONCLUSION}

The DM education group involving peer education and insulin pen demonstration could improve PIR and was well accepted by patients. Further larger multicenter studies are needed.

\section{ACKNOWLEDGEMENTS}

The authors would like to express their gratitude to nurses and healthcare workers at the study site for helping with various 
arrangements. Prof Samuel Wong from the Chinese University of Hong Kong provided valuable opinion and statistical support to the study. We would like to thank all patients who participated in this research.

Funding. This project was self-financed. The Jockey Club School of Public Health and Primary Care, CUHK provided the publication fee.

Authorship. All named authors meet the International Committee of Medical Journal Editors (ICMJE) criteria for authorship for this manuscript, take responsibility for the integrity of the work as a whole, and have given final approval for the version to be published.

Disclosures. Or KY, Yip BHK, Lau CH, Chen $\mathrm{HH}$, Chan YW, and Lee KP have nothing to disclose.

Compliance with Ethics Guidelines. The research was approved by Kowloon West Cluster Research Ethics Committee, Hospital Authority, Hong Kong. All procedures followed were in accordance with the ethical standards of the responsible committee on human experimentation (institutional and national) and with the Helsinki Declaration of 1964, as revised in 2013. Written informed consent was obtained at the time of recruitment from all patients for being included in the study.

Data Availability. The datasets generated during and/or analyzed during the current study are available from the corresponding author on reasonable request.

Open Access. This article is distributed under the terms of the Creative Commons Attribution-NonCommercial 4.0 International License (http://creativecommons.org/licenses/ by-nc/4.0/), which permits any noncommercial use, distribution, and reproduction in any medium, provided you give appropriate credit to the original author(s) and the source, provide a link to the Creative Commons license, and indicate if changes were made.

\section{REFERENCES}

1. Zhou B, Lu Y, Hajifathalian K, et al. Worldwide trends in diabetes since 1980: a pooled analysis of 751 population-based studies with 4.4 million participants. Lancet. 2016;387(10027):1513-30.

2. Davis TM, Colagiuri S, United Kingdom Prospective Diabetes Study. The continuing legacy of the United Kingdom prospective diabetes study. Med J Aust. 2004;180(3):104-5.

3. Inzucchi SE, Bergenstal RM, Buse JB, et al. Management of hyperglycemia in type 2 diabetes: a patient-centered approach: position statement of the American Diabetes Association (ADA) and the European Association for the Study of Diabetes (EASD). Diabetes care. 2012;35:1364-79.

4. Sibal L, Home PD. Management of type 2 diabetes: NICE guidelines. Clin Med. 2009;9(4):353-7.

5. Gherman A, Veresiu I, Sassu R, Schnur J, Scheckner B, Montgomery G. Psychological insulin resistance: a critical review of the literature. Pract Diabetes Int. 2011;28(3):125-8.

6. Polonsky WH, Fisher L, Guzman S, Villa-Caballero L, Edelman SV. Psychological insulin resistance in patients with type 2 diabetes: the scope of the problem. Diabetes Care. 2005;28(10):2543-5.

7. Lee KP. Translation and validation of the insulin treatment appraisal scale in Hong Kong primary care patients. J Diabetes Investig. 2017. https://doi. org/10.1111/jdi.12704.

8. Lee KP. Psycholosocial factors associated with psychological insulin resistance in primary care patients in Hong Kong. J Clin Transl Endocrinol. 2015;2(4):157-62.

9. Snoek FJ, Skovlund SE, Pouwer F. Development and validation of the insulin treatment appraisal scale (ITAS) in patients with type 2 diabetes. Health Qual Life Outcomes. 2007;5(1):69.

10. Tillery E, Bradshaw M, Ngando I. On pens and needles: treatment strategies for psychological insulin resistance in type 2 diabetes mellitus. Ment Health Clin. 2013;3(5):266-70.

11. Allen NA, Zagarins SE, Feinberg RG, Welch G, Welch G. Treating psychological insulin resistance in type 2 diabetes. J Clin Transl Endocrinol. 2017;7:1-6.

12. Aharonson-Daniel L, Paul RJ, Hedley AJ. Management of queues in out-patient departments: the use of computer simulation. J Manag Med. 1996;10(6):50-8. 
13. Hwee J, Cauch-Dudek K, Victor JC, Ng R, Shah BR. Diabetes education through group classes leads to better care and outcomes than individual counselling in adults: a population-based cohort study. Can J Public Health. 2014;105(3):e192-7.

14. Rickheim PL, Weaver TW, Flader JL, Kendall DM. Assessment of group versus individual diabetes education: a randomized study. Diabetes Care. 2002;25(2):269-74.

15. Philis-Tsimikas A, Fortmann A, Lleva-Ocana L, Walker C, Gallo LC. Peer-led diabetes education programs in high-risk Mexican Americans improve glycemic control compared with standard approaches: a Project Dulce promotora randomized trial. Diabetes Care. 2011;34(9):1926-31.

16. Qi L, Liu Q, Qi X, Wu N, Tang W, Xiong H. Effectiveness of peer support for improving glycaemic control in patients with type 2 diabetes: a metaanalysis of randomized controlled trials. BMC Public Health. 2015;15:471.

17. Yoshioka N, Ishii H, Tajima N, Iwamoto Y. Differences in physician and patient perceptions about insulin therapy for management of type 2 diabetes: the DAWN Japan study. Curr Med Res Opin. 2014;30(2):177-83.

18. Heisler M. Overview of peer support models to improve diabetes self-management and clinical outcomes. Diabetes Spectrum. 2007;20:214-21.

19. Bandura A. Health promotion by social cognitive means. Health Educ Behav. 2004;31(2):143-64. https://doi.org/10.1177/1090198104263660.

20. Association AD. Standards of medical care in diabetes-2016: summary of revisions. Diabetes Care. 2016;39(Supplement 1):S4-5.

21. Holmes-Truscott E, Furler J, Blackberry I, O’Neal DN, Speight J, Speight J. Predictors of insulin uptake among adults with type 2 diabetes in the Stepping Up Study. Diabetes Res Clin Pract. 2017;133:204-10.
22. Hermanns N, Mahr M, Kulzer B, Skovlund SE, Haak T. Barriers towards insulin therapy in type 2 diabetic patients: results of an observational longitudinal study. Health Qual Life Outcomes. 2010;8:113.

23. Liebl A, Andersen H, Svendsen AL, Vora J, Yale JF. Resource utilisation and quality of life following initiation of insulin detemir in patients with type 2 diabetes mellitus. Int $\mathrm{J}$ Clin Pract. 2013;67(8):740-9.

24. Holmes-Truscott E, Pouwer F. Further investigation of the psychometric properties of the insulin treatment appraisal scale among insulin-using and noninsulin-using adults with type 2. Health Qual. 2014. https://doi.org/10.1186/1477-7525-12-87.

25. Gherman A, Alionescu A, Sucală M. Cognitive restructuring for psychological insulin resistance: a randomized clinical intervention. J Evidence-Based Psychother. 2017;17(1):129-37.

26. Zhang L, Liu J, Yan C, Zhao Z, Tang J, Ma X. The effect of experiential learning on attitude and willingness to insulin therapy in patients with type 2 diabetes. Int J Clin Exp Med. 2016;9(9):18104-13.

27. Kuo CR, Quan J, Kim S, Tang AH, Heuerman DP, Murphy EJ. Group visits to encourage insulin initiation: targeting patient barriers. J Clin Nurs. 2017;26(11-12):1705-13.

28. Odawara $\mathrm{M}$, Ishii $\mathrm{H}$, Tajima $\mathrm{N}$, Iwamoto $\mathrm{Y}$. Impact of patient attitudes and beliefs to insulin therapy upon initiation, and their attitudinal changes after initiation: the DAWN Japan study. Curr Med Res Opin. 2016;0(0):1-6.

29. Holmes-Truscott E, Pouwer F, Speight J, Speight J. Assessing psychological insulin resistance in type 2 diabetes: a critical comparison of measures. Curr Diabetes Rep. 2017;17(7):46. https://doi.org/10. 1007/s11892-017-0873-4. 